\title{
IMPACTO DO CULTIVO DE CITROSEM PROPRIEDADES QUÍMICAS, DENSIDADE DO SOLO E ATIVIDADE MICROBIANA DE UM PODZÓLICO VERMELHO-AMARELO(1)
}

\author{
A. C. SANCHE ${ }^{(2)}$, A. P. SILVA(3) ${ }^{(\text {C. A.TORME NA(4) } \& \text { A. T. RIGOLIN }}{ }^{(5)}$
}

\begin{abstract}
RESUMO
Quantificaram-se as alterações em algumas propriedades químicas, na densidade do solo e na atividade microbiana, resultantes da reti rada da vegetação natural e da i mplantação da cultura da laranja. Também foi avaliada a influência do local de amostragem, em relação à localização das plantas: na linha de plantio e na entrelinha. 0 estudo foi realizado, em abril de 1996, na fazenda Cambuhy, no município de Matão (SP), amostrando-se um Podzólico Vermelho-Amarelo, cultivado com laranja e sob mata nativa. Amostras foram reti radas em dez pontos nos seguintes locais: na linha eentrelinha da cultura e na mata, nas profundidades de 0-20 e 20-40 cm. Determinaram-se nestas amostras o pH em $\mathrm{CaCl}_{2}$, a saturação por bases, o teor de P disponível, a CTC, o teor de matéria orgânica, a densidade do solo e a atividade microbiana. As comparações foram feitas pelo teste t para amostras independentes entre a mata e a linha da cultura e entre a mata e a entrelinha da cultura. A intensidade das alterações causadas pelo cultivo foi diferente para cada característica avaliada, dependendo da posição considerada em relação à linha da cultura. A retirada da mata e a implantação da cultura da Iaranja alteraram as características químicas, a densidade do solo e a atividade microbiana do solo, princi palmente na camada de 0-20 cm. Na mata, as maiores modificações ocorreram na linha de plantio. 0 cultivo provocou reduções no pH, na saturação por bases, nos teores de matéria orgânica, na CTC e na atividade microbiana do solo. Por outro lado, o cultivo aumentou o teor de P na linha da cultura, bem como a densidade do solo nas duas posições estudadas. 0 valor absoluto de $t$ indicou que a densidade do solo foi a variável mais alterada pelo cultivo, seguida pela CTC e pelo teor de matéria orgânica.
\end{abstract}

Termos de indexação: manejo do solo, laranja Natal, qualidade do solo, degradação do solo, posi ção de amostragem, propriedades físicas do solo.

\footnotetext{
(1) Parte da Tese de Mestrado apresentada pelo primeiro autor ao Curso de Pós-Graduação em Solos e Nutrição de Plantas, E scola Superior de Agricultura Luiz de Queiroz - ESALQ/USP. Trabalho apresentado no XXVI Congresso Brasileiro de Ciência do Solo, Rio de J aneiro (RJ ), de 20 a 26 de julho de 1997. Recebido para publicação em março e aprovado em outubro de 1998.

(2) Aluna do Curso de Pós-Graduação em Solos e Nutrição de Plantas, ESALQ/USP. Bolsista do CNPq.

(3) Professor do Departamento de Ciência do Solo, ESALQ/USP. E-mail: apisilva@carpa.ciagri.usp.br. Bolsista do CNPq.

(4) Professor Adjunto do Departamento deAgronomia, Universidade Estadual de Maringá. Doutorando em Sol os e Nutrição de Plantas. E-mail: catormen@cca.uem.br.

(5) Engenheiro-Agrônomo, Gerente da Divisão de Citros da Cambuhy Agrícola Ltda. Faz. Cambuhy, CEP 04429-310 Matão (SP).
} 


\title{
SUMMARY: IMPACT OF CITRUS CULTIVATION ON CHEMICAL PROPERTIES, BULK DENSITY AND MICROBIAL ACTIVITY OF A YELLOW- RED PODZOLIC SOIL
}

\begin{abstract}
Thechanges in somesoil chemical properties, bulk density, and microbi ol ogical activity due to the replacement of a native forest by orange cultivation wereeval uated in an Yel lowRed Podzol ic Soil. The study was conducted at the Cambuhy orange farm, Matão (SP) in April, 1996. Two areas were selected: (a) a native forest, and (b) a 15-year-old orange plantation. Ten sites wererandomly sel ected in each area and soil sampl es weretaken at 020 and $20-40 \mathrm{~cm}$ depths. In the cultivated area, sampling was carried out in two positions: row (1 $\mathrm{m}$ from thetree), and interrow ( $4 \mathrm{~m}$ from thetree). The samples wereanalyzed for $\mathrm{pH}$, basesaturation percentage, phosphorus, cation exchangecapacity, organic matter, bulk density, and microbiological activity. Statistical analysis was conducted using the test. Orange cultivation had an effect on all the variables, mainly at the $0-20 \mathrm{~cm}$ depth. Cultivation decreased $\mathrm{pH}$, base saturation percentage, organic matter, and cation exchange capacity. Conversely, there was an increase in the phosphorus content in the row and in the bulk density at both positions. The valueindicated that bulk density was the soil property most affected by orange cultivation, foll owed by cation exchange capacity, and organic matter.
\end{abstract}

Indexterms: soil management, natal orange, soil quality, soil degradation, sampling position, soil physical properties.

\section{INTRODUÇÃO}

A citricultura constitui o mais importante grupo da fruticultura mundial (FAO, 1995), do qual oBrasil ocupa lugar de destaque. Estima-seque cerca de um mil hão de toneladas de suco concentrado é vendido no mercado internacional proporcionando ao País uma receita anual de, aproximadamente, US\$1 bilhão (IEA, 1997). O estado de São Paulo é responsável por cerca de $80 \%$ da produção nacional delaranja ede $95 \%$ da produção de suco concentrado. As estimativas são de que 355 milhões de caixas foram col hidas na safra 96/97 (IEA, 1997). Apesar da extensa área citrícola, a produtividade média dos pomares paulistas é baixa, em torno de duas caixas por pé, comparada à média de cinco caixas por pé dos pomares da Flórida - EUA. O incremento de produtividade nos últimos 50 anos foi de 0,5 caixa por planta (Demattê \& Vitti , 1992).

A produtividade da cultura da Iaranja é determinada por fatores genéticos eclimáticos, bem como pelo solo e pelos tratos culturais dados ao pomar. O solo, por meio de suas propriedades físicas, químicas e biológicas, determina o crescimento das plantas. Com a retirada da vegetação natural e implantação das culturas comerciais, ocorrem modificações nas propriedades dos solos. A magnitude e a direção dessas modificações dependem do tipo de solo, do clima, do cultivo e do sistema de manejo utilizado (Scott \& Wood, 1989). Estudos nesse sentido foram realizados por Borges \& Kiehl (1997), os quais constataram que os cultivos de banana e citros el evaram os teores de cátions no solo, principalmente no horizonte superficial de um
Latossolo Amarelo álico. J á os estudos descritos por Lepsch (1980) e Fialho et al. (1991) mostraram que a implantação da cultura do eucal ipto provocou não só aumento na acidez do sol o e no teor de alumínio trocável, como também a redução dos teores de cálcio, magnésio e potássio na camada de $0-20 \mathrm{~cm}$. Os resultados obtidos por Miller et al. (1982) indicaram que o cultivo do solo reduziu em $75 \%$ o teor de matéria orgânica.

Outro ponto importante em relação às al terações nas propriedades do sol o éa posição relativa à linha da cultura. Em pomares de laranja 'Valência', Quaggio (1991) observou que, nas amostras de solo coletadas na linha da cultura (projeção da copa), os valores de saturação por bases foram menores do que nas amostras col etadas na entrelinha da cultura. A acentuada redução da saturação por bases na linha da cultura, em rel ação ao sol o sob mata ea entrel inha da cultura, é associada à remoção de cátions atribuída à absorção pelas plantas, pela lixiviação e erosão.

De forma geral, com a retirada da mata e com o cultivo intensivo, ocorre a degradação da estrutura do solo (Coote \& Ramsey, 1983). A avaliação das alterações no solo, decorrentes do cultivo, deveria ser feita submetendo um solo, sob vegetação natural, às explorações agrícolas e analisando suas propriedades periodicamente (Sanchez, 1976). No entanto, o tempo necessário para a real ização desse tipo de experimento é um fator limitante. A comparação entre áreas cultivadas e vegetação nativa, num mesmo solo, é uma alternativa viável para fazer estimativas mais apropriadas das alterações nas propriedades do solo. 
Poucos são os estudos que utilizam a condição de mata natural como referência para quantificar a natureza e a intensidade das alterações nas propriedades do solo. Para avaliar o impacto da cultura do citros sobreal gumas dessas propriedades, este estudo é fundamentado na hipótese de que o cultivo de citros altera, diferenciadamente, as propriedades químicas, a densidade do solo e a atividade microbiana, dependendo da intensidade dealteração da posi ção em relação à linha da cultura.

Os objetivos deste trabal ho foram: (a) quantificar as alterações nas propriedades químicas, na densidade e na atividade microbiana do solo, resultantes da implantação da cultura de citros; (b) avaliar se essas propriedades foram alteradas de forma e intensidade diferentes, e (c) determinar se a intensidade de alteração dessas propriedades depende da posição em relação à linha da cultura.

\section{MATERIAL E MÉTODOS}

A amostragem foi realizada em abril de 1996 numa área pertencente à Fazenda Cambuhy (Cambuhy Agrícola LTDA), no município de Matão, região central do estado de São Paulo. Segundo a classificação de Köppen, o clima da região é do tipo Cwa: mesotérmico ou subtropical úmido, de inverno seco. A região apresenta um índice pluviométrico variável entre 1.100 e 1.400 mm e a estação seca ocorre entre mai o e setembro. A temperatura média do mês mais frio é inferior a $18^{\circ} \mathrm{C}$ e a média do mês mais quente situa-se entre 23 e $24^{\circ} \mathrm{C}$ (Estação Meteorológica da Fazenda Cambuhy). O solo, nas duas áreas selecionadas, foi classificado como Podzólico Vermel ho-A marelo eutrófico. As características químicas e a análise granulométrica do solo, nas profundidades estudadas, estãodescritas no quadro1.
Foram selecionadas duas áreas próximas, sendo uma sob mata nativa (floresta latifoliada semicaducifólia ou mata de planalto) e outra sob cultivo de citros (Iaranja Natal Citrus sinensis L. Osbeck) sobre o porta-enxerto limão-cravo, implantado no espaçamento de $8 \times 6 \mathrm{~m}$. O pomar foi estabel ecido em março de 1981, utilizando o sistema convencional de preparo do solo. Anteriormente, a área tinha sido utilizada com pastagem por 10 anos. Durante a safra 1996/1997, foi feita a aplicação de 1,5 t ha-1 de cal cário dol omítico. Na adubação, foram aplicados 2,8 kg por planta do fertilizante comercial 21-07-14, parcelado em três vezes: em outubro e dezembro de 1996 e em fevereiro de 1997. Na linha da cultura, o controle de ervas daninhas foi feito com duas aplicações de herbicida glifosato, na dosagem de $2,5 \mathrm{~L}$ ha-1, as quais foram feitas em novembro de 1996 e em fevereiro de 1997. Na entrelinha da cultura, o controle de plantas daninhas foi realizado com três roçadas: em setembro e dezembro de 1996 e em fevereiro de 1997.

Foram selecionados, aleatoriamente, dez pontos na mata, dez pontos na linha da cultura (1 m do tronco da planta) e dez pontos na entrelinha da cultura (4 m do tronco da árvore). Em cada ponto, nas profundidades de 0-20 e $20-40 \mathrm{~cm}$, foi coletada uma amostra deformada com cerca de $250 \mathrm{~g}$ de solo e outra amostra indeformada com anel metálico ( $5 \mathrm{~cm}$ de diâmetro e $5 \mathrm{~cm}$ de altura).

A densidade do solo foi determinada, nas amostras indeformadas, de acordo com Blake \& Hartge (1986). As análises químicas foram efetuadas nas amostras deformadas secas ao ar e passadas por peneira de $2 \mathrm{~mm}$ de diâmetro de mal ha. Determi nouse o pH do solo em solução centimolar de doreto de cálcio (Raij \& Quaggio, 1983); o P foi extraído com resina trocadora de íons e determinado pel o método do complexo fosfomolíbdico, empregando-se ácido

Quadro 1. Propriedades químicas e granulometria das camadas de 0-20 e 20-40 cm

\begin{tabular}{|c|c|c|c|c|c|c|c|c|c|c|c|c|c|}
\hline Local & pH $\mathrm{CaCl}_{2}$ & M.O. & $\mathbf{P}$ & $\mathbf{K}$ & $\mathrm{Ca}$ & Mg & $\mathbf{H}$ & $\mathbf{S}$ & $\mathbf{T}$ & $\mathbf{v}$ & Areia & Silte & Argila \\
\hline & & $\mathrm{g} \mathrm{kg}^{-1}$ & $\mathrm{mg} \mathrm{dm}^{-3}$ & \multicolumn{6}{|c|}{$\mathrm{mmol}_{\mathrm{c}} \mathrm{dm}^{-3}$} & $\%$ & \multicolumn{3}{|c|}{$\mathrm{g} \mathrm{kg}^{-1}$} \\
\hline \multicolumn{14}{|c|}{$0-20 \mathrm{~cm}$} \\
\hline Mata & 5,4 & 25,2 & 5,1 & 0,22 & 6,1 & 1,5 & 2,1 & 7,82 & 9,92 & 78,8 & 790 & 60 & 150 \\
\hline Linha & 5,2 & 12,6 & 30,6 & 0,13 & 1,6 & 0,37 & 3,05 & 2,1 & 5,15 & 40,8 & 820 & 50 & 130 \\
\hline E. linha & 5,5 & 13,1 & 5 & 0,17 & 2,7 & 1,35 & 1,35 & 4,22 & 5,57 & 75,8 & 780 & 60 & 160 \\
\hline \multicolumn{14}{|c|}{$20-40 \mathrm{~cm}$} \\
\hline Mata & 5,0 & 15,8 & 2,6 & 0,22 & 3,58 & 1,02 & 2,10 & 4,82 & 6,92 & 69,7 & 790 & 55 & 155 \\
\hline Linha & 4,2 & 11,2 & 3,1 & 0,10 & 2,11 & 1,07 & 1,52 & 3,28 & 4,8 & 68,3 & 800 & 40 & 160 \\
\hline E. linha & 4,4 & 11,2 & 9,9 & 0,15 & 1,84 & 0,44 & 2,34 & 2,43 & 4,77 & 50,9 & 780 & 60 & 160 \\
\hline
\end{tabular}

Granulometria determinada conforme EMBRAPA (1979). 
ascórbico como redutor (Raij \& Quaggio, 1983). A CTC e a saturação por bases foram calculadas conforme Camargo et al. (1986). O teor de matéria orgânica foi determinado por oxidação com solução de dicromato de potássio (Camargo et al., 1986). A atividade microbiana foi determinada nas mesmas amostras utilizadas para a análise de fertilidade do solo, por meio do método da radiorrespirometria descrito por Freitas et al. (1979).

Os dados foram anal isados usando o testet para amostras independentes (SAS, 1991), ocasião em que foram feitas comparações entre a mata e a linha e entre a mata e a entrelinha da cultura.

\section{RESULTADOS E DISCUSSÃO}

O cultivo da laranja alterou, significativamente, as propriedades quími cas do sol o. Os val ores médios do $\mathrm{pH}$, nas áreas sob mata e cultivo, nas profundidades de 0-20 e 20-40 cm, são apresentados na figura $1 . \mathrm{O} \mathrm{pH}$ variou com a posição amostrada na área de cultivo. A redução do pH foi significativa somente quando considerada a área da linha da cultura, que, em relação à mata, diminuiu 1,66 unidades, para a profundidade de $0-20 \mathrm{~cm}$, e 0,63 unidades, para a profundidade de $20-40 \mathrm{~cm}$. A redução diferenciada do $\mathrm{pH}$ do solo também foi constatada por Cerri (1986) e Lima (1995), comparando solos cultivados com cana-de-açúcar e sob vegetação natural. Esses autores verificaram que esse comportamento estava associado à diminuição dos teores de cátions trocáveis.

A redução do $\mathrm{pH}$, na linha da cultura, também pode estar relacionada com a aplicação de corretivos e fertilizantes na cultura dos citros. O calcário é normalmente distribuído a lanço na área total do pomar. No entanto, Luz (1995) constatou que, durante a aplicação do calcário a lanço, o fornecimento efetivo da dose recomendada foi de $57,7 \%$, para a linha da cultura, e de $81,4 \%$, para a entrelinha da cultura. Por outro lado, a adubação com fontes nitrogenadas é localizada na linha da cultura, acentuam as diferenças no processo de acidificação do solo nesta posição (Quaggio, 1991; Vitti et al., 1996).

Os resultados indicaram que, nas profundidades de 0-20 e 20-40 cm, houve redução significativa na saturação por bases na linha da cultura, em comparação com a mata e entrelinha (Figura 2). Os valores de saturação por bases, na mata e na entrel inha da cultura, estão classificados como altos (Raij, 1991). Na linha da cultura, o valor médio foi de $41 \%$, para a camada de $0-20 \mathrm{~cm}$, e de $51 \%$, para a camada de $20-40 \mathrm{~cm}$, sendo similares aos valores médios encontrados nas áreas cultivadas com citros no estado de São Paulo (Quaggio, 1996).

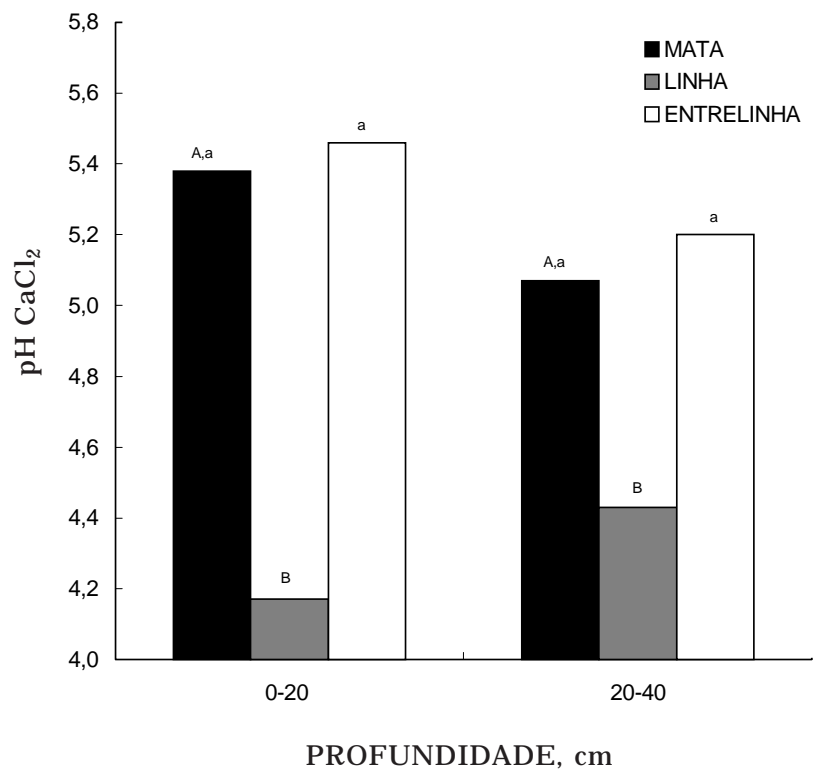

Figura 1. Valores médios de pH em $\mathrm{CaCl}_{2}$, nas profundidades de 0-20 e 20-40 cm, para os três locais estudados. As letras maiúsculas comparam as áreas sob mata e linha da cultura, a $5 \%$ pelo teste $t$. As letras minúsculas comparam a mata e a entrelinha da cultura, a $5 \%$ pelo teste $t$.

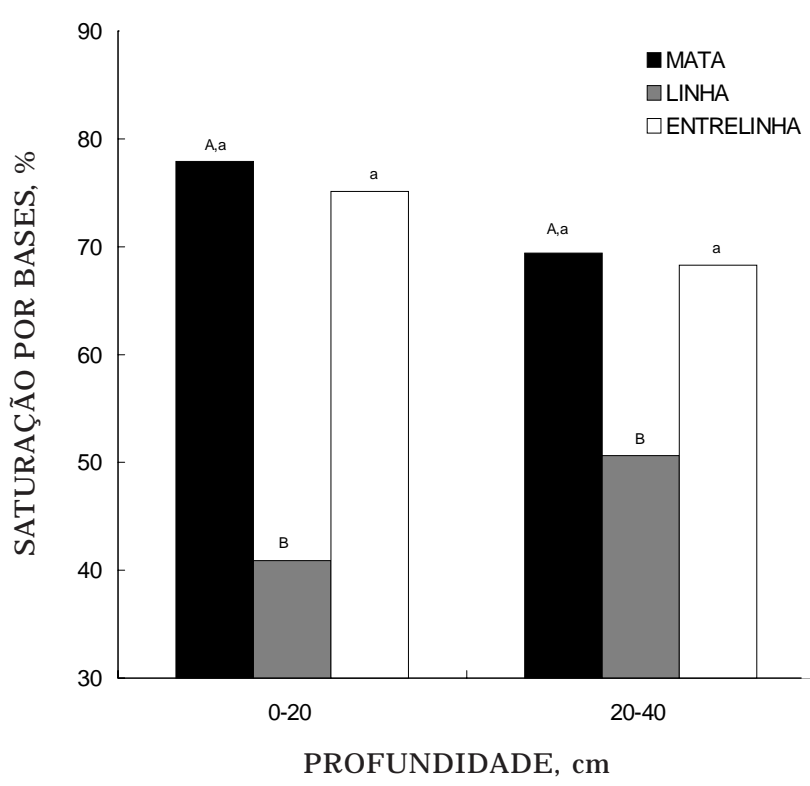

Figura 2. Valores médios de saturação por bases, nas profundidades de 0-20 e 20-40 cm, para os três locais estudados. As letras maiúsculas comparam as áreas sob mata e linha da cultura, a $5 \%$ pelo teste $t$. As letras minúsculas comparam a mata e a entrelinha da cultura, a $5 \%$ pelo teste $t$. 
De acordo com as recomendações do Grupo Paulista deAdubação e Calagem para Citros (1994), a faixa adequada de saturação por bases encontrase entre 60 e 70\%. Na entrelinha, a saturação por bases é considerada adequada para a cultura, não diferindo, significativamente, da condição sob mata. Por outrolado, na linha da cultura, a saturação por bases está abaixo daquela considerada adequada para o cultivo dos citros, corroborando os resultados apresentados por Quaggio (1991).

Em relaçãoaoteor de $\mathrm{P}$, observaram-se diferenças significativas entre as áreas com mata e cultivo, quando considerada a linha da cultura (Figura 3). E $m$ relação à mata, o teor de $P$ na linha foi, aproximadamente, seis vezes maior na camada de $0-20 \mathrm{~cm}$ e quatro vezes maior na camada de $20-40 \mathrm{~cm}$.

Os maiores valores de $\mathrm{P}$ na linha da cultura são justificados, provavelmente, pela adição desse nutriente por meio da adubação. Além disso, outros fatores podem contribuir para o acúmul o de $P$ nesta posição, tais como a baixa mobilidade do $\mathrm{P}$ no solo e a reduzida exportação desse nutriente pelas col heitas (Pratt et al., 1956). Resultados similares foram apresentados por Borges \& Kiehl (1997).

A CTC foi muito alterada com a retirada da mata e implantação da cultura da Iaranja, nas duas posições e profundidades amostradas (Figura 4), concordando com os resultados obtidos por Aina (1979) e Chan et al. (1992).

E m sol os tropicais, al tamente intemperizados ou não, deve-se ressaltar a importância da matéria orgânica para a manutenção da CTC do solo, principalmente em superfície (Sanchez, 1976). Os resultados obtidos indicaram quehouve decréscimo linear da CTC da camada de 0-20 para a de $20-40 \mathrm{~cm}$ com a diminuição da matéria orgânica do solo, indicando que a redução da CTC (Figura 4), a partir da implantação da cultura, deveu-se à perda da matéria orgânica, confirmando as observações de Brans (1971). O solo cultivado apresentou teores de matéria orgânica mais baixos do que o solo sob mata natural, nas duas camadas consideradas, independentemente da posição da cultura (Figura 5).

Diversos autores concordam que, nos trópicos úmidos, a tendência geral é de um decréscimo nos teores de matéria orgânica do solo após a retirada da mata nativa (Santos \& Grisi, 1981; Miller et al., 1982). As perdas de matéria orgânica foram, em média, de $50 \%$, na camada de $0-20 \mathrm{~cm}$, e de $30 \%$, na camada de $20-40 \mathrm{~cm}$, sendo mais acentuadas na camada de 0-20 cm, confirmando as observações de Machado et al. (1981). O maior teor de matéria orgânica na área sob mata podeestar associado com a maior restituição de resíduos vegetais ao solo (Cunnigham, 1963; Godefroy \& J acquin, 1975). Em solos tropicais, a retirada da mata e a adoção de sistemas agrícol as promovem redução nos teores de

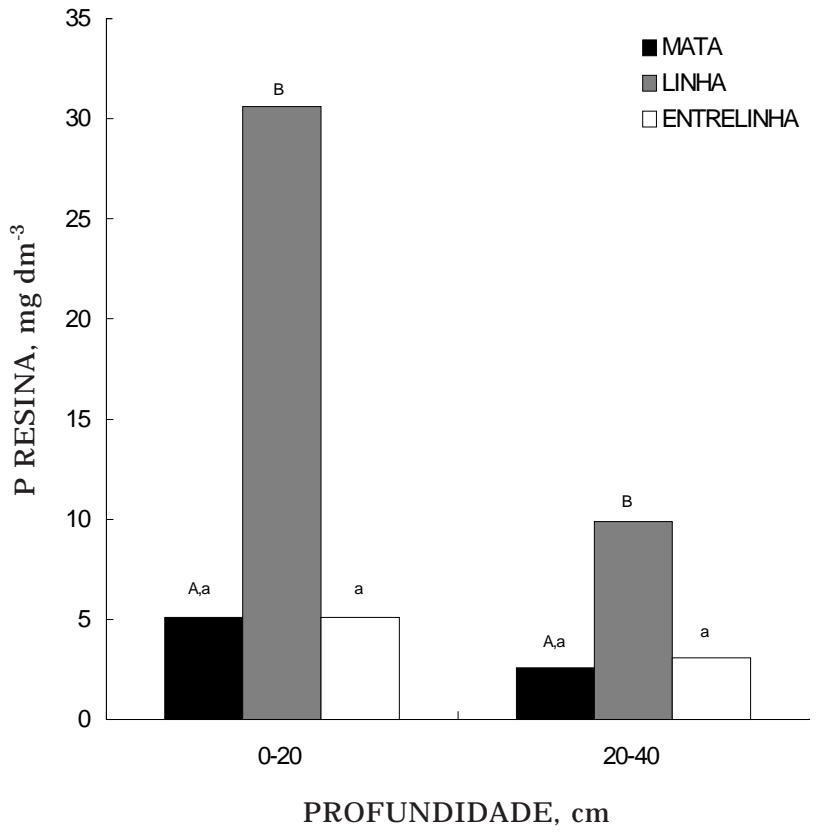

Figura 3. Valores médios de $P$, nas profundidades de 0-20 e 20-40 cm, para os três locais estudados. As letras maiúsculas comparam as áreas sob mata e a linha da cultura, a $5 \%$ pelo teste $t$. As letras minúsculas comparam a mata e a entrelinha da cultura, a $5 \%$ pelo teste $t$.

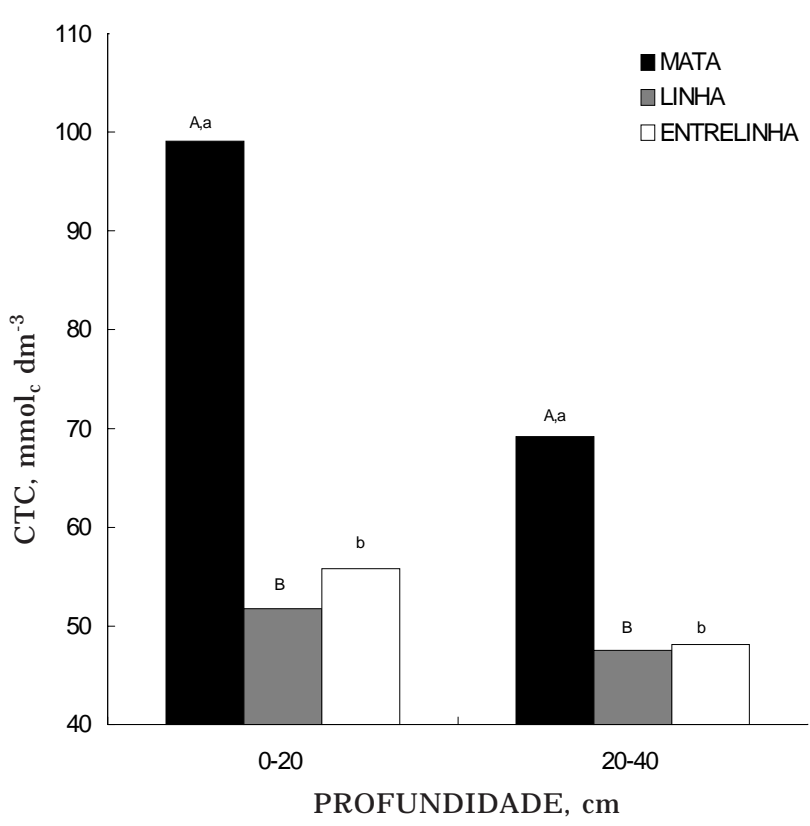

Figura 4. Valores médios de CTC, nas profundidades de 0-20 e 20-40 cm, para os três locai s estudados. As letras maiúsculas comparam as áreas sob mata e linha da cultura, a $5 \%$ pelo teste $t$. As letras minúsculas comparam a mata e a entrelinha da cultura, a $5 \%$ pelo teste $t$. 


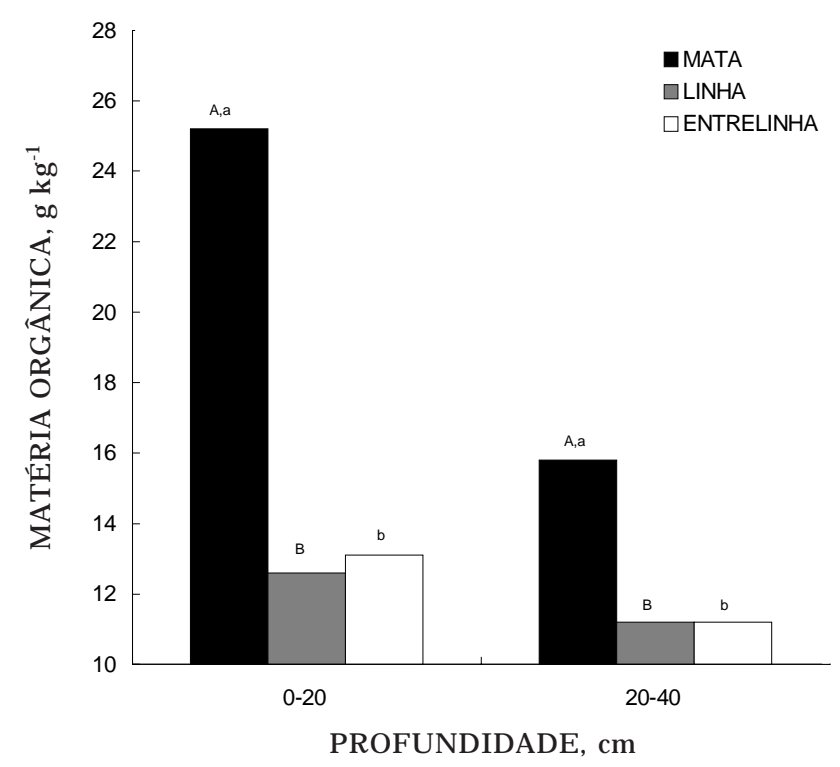

Figura 5. Valores médios de matéria orgânica, nas profundidades de $0-20$ e $20-40 \mathrm{~cm}$, para os três locais estudados. As letras maiúsculas comparam as áreas sob mata e linha da cultura, a $5 \%$ pelo teste $t$. As letras minúsculas comparam a mata e a entrelinha da cultura, a $5 \%$ pelo teste $t$.

matéria orgânica dos sol os (Miller et al., 1982; Chan \& M ead, 1988). Associadas a esse processo, estão as perdas por erosão, as quais são maiores nas áreas cultivadas, reduzindo o teor de matéria orgânica na superfície (Monreal \& J anzen, 1993). Na profundidade de $0-20 \mathrm{~cm}$, o aumento nos teores médios de matéria orgânica pode estar associado com a manutenção dos restos culturais das plantas daninhas.

O cultivoalterou, significativamente, a densi dade do solo (Figura 6). Nas áreas sob cultivo, a densidade do solo foi maior nas duas posições avaliadas, em relação à mata. O aumento da densidade do solo com o cultivo pode estar relacionado com a compactação do sol o causada pel o tráfego contínuo de máquinas, como constatado por Cassel (1983), Carter (1987) e Hajabbasi et al. (1997).

O tráfego contínuo de máquinas na cultura da laranja é devido ao el evado número de operações mecanizadas para as práticas de adubação, pulverização e controle de plantas daninhas (Cintra et al., 1983; Tersi \& Rosa, 1995). Conforme Hajabbasi et al. (1997), essas condições provocam decréscimo da macroporosidade, contribuindo para uma elevação nos valores da densidade do solo. O aumento da densidade do solo devido ao cultivo também pode estar relacionado com a perda de matéria orgânica (Bauer \& Black, 1981; Scott \& Wood, 1989).

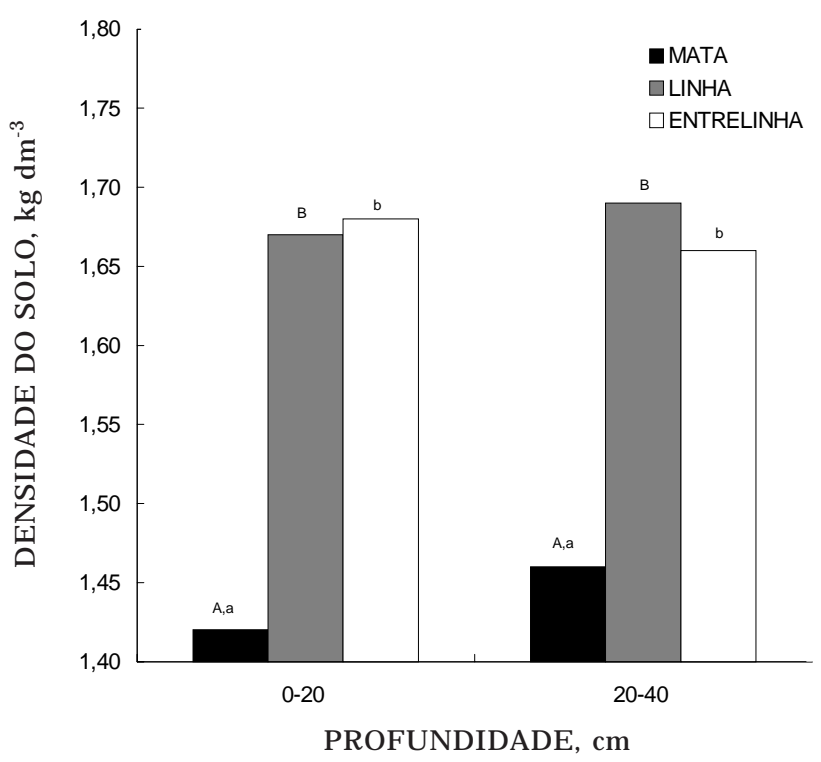

Figura 6. Valores médios de densidade do solo, nas profundidades de 0-20 e $20-40 \mathrm{~cm}$, para os três locais estudados. As letras maiúsculas comparam as áreas sob mata e linha da cultura, a $5 \%$ pelo teste $t$. As letras minúsculas comparam a mata e a entrelinha da cultura, a $5 \%$ pelo teste $t$.

A atividade microbiana foi alterada pelo cultivo do solo (Figura 7). As diferenças ficaram restritas à camada de $0-20 \mathrm{~cm}$. As amostras provenientes do solo sob mata apresentaram atividade mi crobiana maior do que as amostras provenientes do solo cultivado.

A atividade microbiana no sol o cultivado podeter sido limitada pela redução dos teores de matéria orgânica e pela saturação por bases, bem como pela aci dificação do solo (Hunter, 1972). A maior redução da atividade microbiana em profundidade, no solo sob mata, está, provavel mente, relacionada com as diferenças nos teores de matéria orgânica entre as profundidades.

A importância relativa das variáveis estudadas pode ser identificada pelos valores absolutos de $t$ (F igura 8). Valores superiores a 2,1 indicam diferenças significativas a $5 \%$. Comparando a mata com a área cultivada, quanto maior ovalor det maior o impacto do cultivo sobre a variável.

O impacto da implantação da cultura da laranja foi mais acentuado na camada de $0-20 \mathrm{~cm}$. A densidade do sol o foi a variável mais alterada pelo cultivo. Para a profundidade de $0-20 \mathrm{~cm}$, a comparação entre a mata e a entrelinha resultou em t de 8,95; para a comparação entre mata ea linha, o valor de t foi de 8,87. A el evação da densidade do solo revela que as condições físicas do sol o também podem estar comprometendo o potencial máximo de produção de laranja nessas áreas. A compactação do 


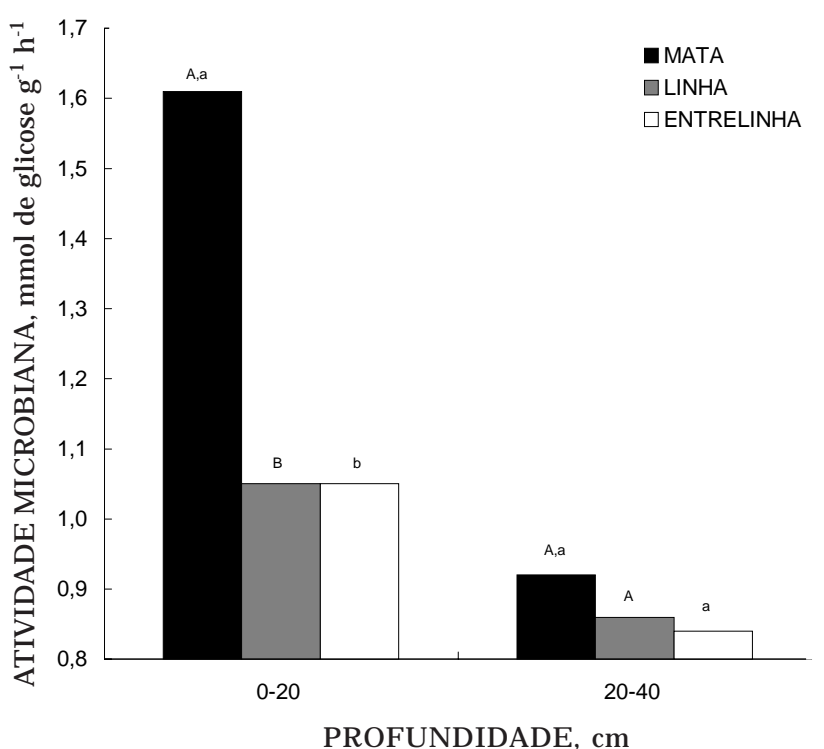

Figura 7. Valores médios de atividade microbiana, nas profundidades de $0-20$ e $20-40 \mathrm{~cm}$, para os três locais estudados. As letras maiúsculas comparam as áreas sob mata e linha da cultura, a $5 \%$ pelo teste $t$. As letras minúsculas comparam a mata e a entrelinha da cultura, a $5 \%$ pelo teste $t$. solo envolve a deterioração de suas propriedades físicas diretamenterelacionadas com a produtividade da laranja, tais como a resistência do sol oà penetração das raízes ea aeração (Abercrombie\& Du Plessis, 1995).

A redução da matéria orgânica e da CTC do solo foi significativa na área cultivada, sendo pouco influenciada pela posição considerada dentro da cultura. Por outro lado, nota-se que as variáveis $\mathrm{pH}$ e saturação por bases e P disponível são bastante sensíveis à posição considerada. Os val ores det para essas duas variáveis, na comparação entre mata e entrelinha da cultura, foram inferiores a 2,1 nas duas profundidades. $\mathrm{O}$ mesmo não ocorreu quando a comparação foi feita entre mata e linha da cultura (Figura 8). Os resultados demonstram que a adubação com $P$ foi imprescindível para viabilizar o cultivo de citros, uma vez que os teores de $\mathrm{P}$ no solo sob mata são limitantes para essa cultura.

\section{CONCLUSÕES}

1. A retirada da mata ea implantação da cultura da Iaranja alteraram as características químicas, a densidade do solo e a atividade microbiana do solo, principalmente na camada de $0-20 \mathrm{~cm}$.

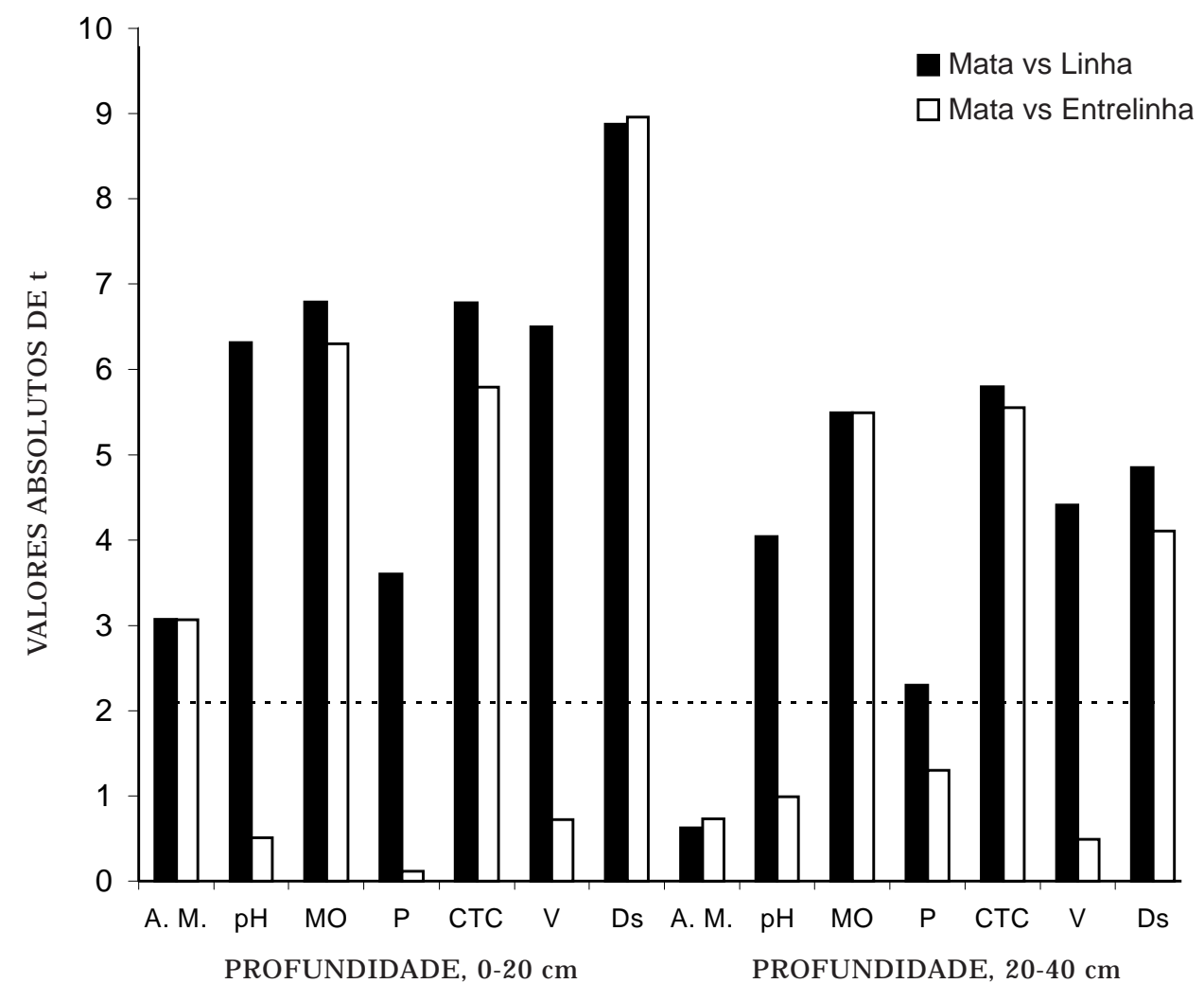

Figura 8. Valores absolutos de t para as variáveis estudadas. A.M. =Atividade microbiana; Ds =densidade do solo. 
2. O cultivo modificou diferentementeas variáveis analisadas. As maiores modificações foram constatadas na linha de cultivo de citros, como indicado pela redução no pH, na saturação por bases, na matéria orgânica, na CTC do sol o e na atividade microbiana e pelo aumento no teor de P. E m relação à mata, a densidade do solo foi maior na área cultivada nas duas posições estudadas.

3. O valor absoluto de $t$ para as variáveis analisadas indicou que a densidade do solo foi a variável mais al terada pel o cultivo, seguida pela CTC e pelo teor de matéria orgânica do solo.

\section{LITERATURA CITADA}

ABERCROMBIE, R.A. \& DU PLESSIS, S.F. The effect of alleviating soil compaction on yield and fruit size in an established Navel orange orchad. J. South Afr. Soc. Hort. Sci., 5:85-89, 1995.

AINA, P.O. Soil changes resulting from management practices in Western Nigeria. Soil Sci. Soc. Am. J., 43:173-177, 1979.

BAUER,A.\& BLACK,A.L. Soil carbon, nitrogen and bulk density comparisons in two cropland tillage systems after 25 years and in virgin grassland. Soil Sci. Soc. Am. J ., 45:1166-1170, 1981.

BLAKE, G.R. \& HARTGE, K.H. Bulk density. In: KLUTE, A. Methods of soil analysis - physical and mineralogical methods. 2.ed. Madison, ASA - SSSA, 1986. p.363-375.

BORGES, A.L. \& KIEHL, J .C. Cultivo de frutíferas perenes e de mandioca sobre as propriedades químicas de um $L$ atossolo Amarelo álico de Cruz das Almas (BA). R. Bras. Ci. Solo, 21:341-345, 1997.

BRANS, E. Continuous cultivation of West African soils: organic matter diminuition and effects of applied lime and phosphorus. Plant Soil, 35:401-414, 1971.

CAMARGO, O.A.; MONIZ, A.C.; J ORGE, J .A. \& VALADARES, J.M.A.S. Métodos de análise química, mineralógica e física de sol os do Instituto Agronômico de Campinas. Campinas, Instituto Agronômico, 1986. 94p. (Boletim Técnico, 106)

CARTER, M.R. Physical properties of some Prince E dward I sland soils in relation to their tillage. Can. J. Soil Sci., 67:473483, 1987.

CASSEL, D.K. Spatial and temporal variability of soils physical properties following tillage of N orfolk loamy sand. Soil Sci. Soc. Am. J ., 47:196-201, 1983.

CERRI, C.C. Dinâmica da matéria orgânica do solo no agroecossistema cana-de-açúcar. Piracicaba, Escola Superior de Agricultura Luiz de Queiroz, 1986. 197p. (Tese de Livre Docência)

CHAN, K.Y. \& MEAD, J .A. Surface physical properties of a sandy loam soil under different tillage practices. Aust. J. Soil Res., 26:549-559, 1988.

CHAN, K.Y.; ROBERTS, W.P. \& HEEMAN, D.P. Organic carbon and associated soil properties of a red earth after 10 years of rotation under different stubble and tillage practices. Aust. J. Soil Res., 30:71-83, 1992.
CINTRA, F.L.D.; COELHO, Y.S. \& CUNHA SOBRINHO, A.P. Caracterização física do sol o submetido à prática de manejo em pomar de Iaranja "Baianinha". Pesq. Agrop. Bras., 18:173-179, 1983.

COOTE, D.R. \& RAMSEY, J.F. Quantification of the effects of over 35 years of intensive cultivation on four soils. Can. J . Soil. Sci., 63:1-14, 1983.

CUNNIGHAM, R.K. The effect of clearing a tropical forest soil. J. Soil Sci., 14:334-345, 1963.

DEMATTÊ, J.L.I \& \& VITTI, G.C. Alguns aspectos relacionados ao manejo de solos para os citros. In: SIMPÓSIO INTERNACIONAL DE CITROS: FISIOLOGIA, 2., Bebedouro, 1992. Anais. Campinas, Fundação Cargill, 1992. p.67-99.

EMPRESA BRASILEIRA DE PESQUISA AGROPECUÁRIA EMBRAPA. Serviço Nacional de Levantamento e Conservação de Solos. Manual de métodos de análise de solo. Rio de J aneiro, EMBRAPA, SNLCS, 1979. Não paginado.

FAO. Statistical Series. Rome, 1995. v.48. p.61.

FIALHO, J.F.; BORGES, A.C. \& BARROS, N.F. Cobertura vegetal e as características químicas e físicas e atividade da microbiota de um Latossolo Vermelho-Amarelo distrófico. R. Bras. Ci. Solo, 15:21-28, 1991.

FREITAS, J.R.; NASCIMENTO, V.F.; VOSE, P.B. \& RUSCHEL, A.P. Estimativa da atividade da microflora heterotrófica em solo terra roxa estruturada usando respirometria com glicose - 14C. Energ. Nucl. Agric., 1:123-130, 1979.

GODEFROY, J. \& J ACQUIN, F. Relation entre la stabilité structurale des sols cultivés et les apports organiques en conditions tropicales: comparasion avec les sols forestiers. Fruits, 30:595-612, 1975

GRUPO PAULISTA DE ADUBAÇÃO E CALAGEM PARA CITROS. Recomendações de adubação e calagem para citros no estado de São Paulo. 3.ed. Cordeirópolis, 1994. 27p.

HAJ ABBASI, M.A.; J ALALIAN, A. \& KARIMZADEH, H.R. Deforestation effects on soil physical and chemical properties, Lordegan, Iran. Plant Soil, 190:301-308, 1997.

HUNTER, S.H. Inorganic nutrition. Ann. Rev. Microbiol., 26:313346, 1972.

INSTITUTO DE ECONOMIA AGRÍCOLA -IEA. Os números da citricultura. São Paulo:IEA, 1997. 28p.

LEPSCH, I.F. Influência do cultivo de Eucalyptus e Pinus nas propriedades químicas de solos sob cerrado. R. Bras. Ci. Solo, 4:103-107, 1980

LIMA, J.M.J.C. Alterações de propriedades de solos cultivados com cana-de-açúcar. Piracicaba, Escola Superior de Agricultura Luiz de Queiroz, 1995. 173p. (Tese de Doutorado)

LUZ, P.H.C. Efeitos de modos de aplicação e incorporação de calcário e gesso em pomares de citros. Piracicaba, Escola Superior deAgricultura Luiz de Queiroz, 1995. 159p. (Tese de Doutorado)

MACHADO, J .A.; SOUZA, D.M. \& BRUM, A.C.R... Efeito de anos de cultivo convencional em propriedades físicas do solo. R. Bras. Ci. Solo, 5:187-189, 1981. 
MILLER, R.H.; NICHOLAIDES, J . .; SANCHEZ, P.A. \& BANDY, D.E. Soil organic matter considerations in agricultural systems of the humid tropics. In: COLÓQUIO REGIONAL SOBRE MATÉRIA ORGÂNICA DO SOLO, 1., Piracicaba, 1982. Anais. Piracicaba, CENA, 1982. p.105-110.

MONREAL, C.N. \& J ANZEN, H.H. Soil organic carbon dynamics after 80 years of cropping a Dark Brown Chernozem. Can. J. Soil Sci., 73:133-136, 1993.

PRATT, P.F.; J ONES, W.W. \& CHAPMAN, H.D. Changes in phosphorus in an irrigated soil during 28 years of differential fertilization. Soil Sci., 36:295-306, 1956.

QUAGGIO, J.A. Análise de solo para citros: métodos e critérios para interpretação de resultados. In: SEMINÁRIO INTERNACIONAL DE CITROS - NUTRIÇÃO E ADUBAÇÃO, 5., Bebedouro, 1996. Anais. Campinas, Fundação Cargill, 1996. p.95-113.

QUAGGIO,J .A. Respostas da laranjeira valência (Citrus si nensis L. Osbeck) sobre limoeiro cravo (Citrus limonia L. Osbeck) a calagem e ao equilíbrio de bases num L atossolo Vermel hoEscuro de textura argilosa. Piracicaba, Escola Superior de Agricultura Luiz de Queiroz, 1991. 107p. (Tese de Doutorado)
RAIJ , B. van \& QUAGGIO, J.A. Métodos de análise de solo para fins de fertilidade. Campinas, I nstituto Agronômico, 1983. 31p. (Bol etim Técnico, 81)

RAIJ, B. van. Fertilidade do solo e adubação. Piracicaba, Agronômica Ceres, Potafos, 1991. 343p.

SANCHEZ, P.A. Properties and management of soils in the tropics. New York, J ohn Willey \& Sons, 1976. 619p.

SANTOS, O.M. \& GRISI, B.M. Efeito do desmatamento na atividade dos microrganismos de solo de terra-firme na Amazônia. Acta Amazon., 11:97-102, 1981.

SAS INSTITUTE. SAS/STAT procedure guide for personal computers. 5. ed. Cary, NC. 1991.

SCOTT, H.D. \& WOOD, L.S. I mpact of crop production on the physical status of a Typic Albaqualf. Soil Sci. Soc. Am. J., 53:1819-1825, 1989.

TERSI, F.E.A. \& ROSA, S.M. A subsolagem no manejo de solo para os pomares de citros. Laranja, 16:289-298, 1995.

VITTI, G.C.; LUZ, P.H.C.; LEÃO, H.C. \& SILVA, M.M. Técnicas de utilização de calcário e gesso na cultura dos citros. In: SEMINÁRIO INTERNACIONAL DE CITROS NUTRIÇÃO E ADUBAÇÃO, 4., Bebedouro, 1996. Anais. Campinas, Fundação Cargill, 1996. p.131-160. 